\title{
The Strategy of Implementation of Social Health Insurance Scheme in Albania
}

Degjoni Rudina

\begin{abstract}
This abstract is to provide a concise description of the strategy of implementation of social health insurance scheme in Albania. The health insurance scheme in Albania was established from 1995 year $^{1}$ and it covered a basic list of reimbursable drugs and the payment of family doctors in the system since its inception. From year to year, the scheme evolved gradually, with different expanding the range of the covered services throught shifting from undifferentiated funding to payment for health services packages in Albania. From the year 2013, Health Insurance Fund of Albania ${ }^{2}$ takes the decisions to change the mechanisms of the health insurance scheme. The new health insurance scheme covers the primary health care service, the hospitals service and the list of reimbursamble drugs. This abstract proposes which are the principles on which the health insurance scheme wills based in Albania, which are the categories benefiting from the health insurance scheme and which are the amount of compulsory health insurance contribution. In brief, the current social helath insurance scheme situation in Albania if includes any problems as health financing; if the social health insurance scheme is consolidated. These proposals in this abstract are ambitious and require detailed implementation of social helath insurance scheme and planning for the Albanian population how to be insured in the health sector of Albania.
\end{abstract}

Keywords: health insurance scheme of Albania, social implementation, categories of benefiting.

\section{Introduction}

The model of health insurance scheme in the Republic of Albania is a mix model of Bischmark and Beveridge model, wich is based on mandatory and voluntary contributions, as well as in funding from the state budget. According to the Law no.10383, dated 24.02.2011, "On compulsory healthcare insurance in the Republic of Albania"3, as amended, the compulsory insurance finances the compulsory insurance services packages that include medical check-ups, examinations and treatment in public primary health care centers and public hospitals, medical check-ups, examinations and treatments in private primary health care and hospital providers, drugs, medical products and treatments by contracted providers of health services. Health insurance scheme is based on the model of the single payer, which is Compulsory Health Insurance Fund that manages the scheme in accordance with national health care policies.

The Fund of Albania uses methods of health services payment in order to influence the growth of access, preventation and improvement of population health indicators in the Republic of Albania.

The mechanism of the health insurance scheme implementation is the annual contract with health public and health private providres for the provision of health services packages in Albania. The Compulsory health insurance of Albania is based on the contributions of employees, employers, state and other sources for other people, based on the principle of solidarity. The Compulsory health care insurance scheme of Albania intends to cover the population with health care services, financed by the public and private sector. In the Republic of Albania the paying social security and health insurances contributions makes it possible to benefit from the two Laws of Albania, the first one is a social security law 4 and the second one is the health insurance Law 5 . In the Republic of Albania the contributions are collected by the tax authorities on behalf of the Social Insurance Institute and the Institute of Health Insurance. The minimum salary considered for calculating social security contributions as from 08.01 .2013 is 19,026 ALL and the maximum monthly salary is $95,130 \mathrm{ALL}^{6}$. But, in the employment relationship, the employer is obligated to implement the minimum monthly basic salary nationwide ${ }^{7}$, which from the date 07.01 .2013 is 22000 ALL. As of January 1, 2014 health insurance

1 Law No 7870 date 13.10.1994 "On Health Insurance in Albania"

2 Law no.10383, dated 24.02.2013, "On compulsory healthcare insurance in the Republic of Albania"

${ }^{3}$ Fjoralba Memia (2014) "The benefits of Compulsory Health Insurance Fund of Albania"

${ }^{4}$ Law no. 7703 date 11.05.1993 "The Social Security Law in Albania"

5 Law no. 7870 date 13.10.1994 "Health Insurance Law in Albania"

${ }^{6}$ DCM no. 581, dated 07/17/2013

7 DCM no. 573, dated 03/07/2013 
contributions are calculated on the gross salary and not on the minimum/maximum wage as previously estimated ${ }^{1}$. The contribution for Health Insurance in Albania is $3.4 \%$, while the Social Security contribution is $24.5 \%$. The employer pays $16.7 \%$ of contributions, while the employee pays $11.2 \%$ of contributions.

Compared with countries in the region, Serbia has the highest rate of social security contributions, followed by Bosnia Herzegovina and the Republic of Albania.

\section{Chapter I}

\section{Health Insurance Scheme of Albania}

\section{The primary health care}

The health Insurance scheme of Albania covers the primary health care service other the community centres. The primary health care services in Albania should provide health services in quantity and quality, in accordance with Health Care Law, the Law on Drugs, the professional protocols adopted, the code of ethics in Albania and medical deontology, standards and norms. The Ministry of Health established the Order of Physicians and the Order of Nurses, Law "On Protection of Personal Data" and Insurance Legislation Health. The services will be provided without discrimination of any kind of discrimination in Albania, with fully respect and maintain the confidentiality of all data and information of every person, his dignity and privacy. The primary health care service in Albania is responsible for the registration of inhabitants by medical personnel contracted. All the residents of the Republic of Albania choose GP and family doctor based on the principle of free choice. The number of residents registered to a family doctor, it must be in accordance with the standards determined by the Ministry of Health of Albania. The family doctors forced to make health coverage to residents on rate standards approved only when there is no alternative. The family doctors recommended the population of Albania by the community to registering with the same doctor of region. The residents of Albania have the right to change the family doctor no more frequently than once a year, when they have completed derecognition previous doctor. The primary health care service should will guarantees that their staffs provide quality health services, based on the medical knowledge and medical technology, which will make the primary health care service to put in disposal all the diagnostic tools, medical devices and drugs prescribed by the protocols.

\section{The hospital service}

In Albania, the major provider of health care services is the government. The hospital care in Albnia is organised on three levels care:

\section{The primary health care level that provided at health centres and polyclinics;}

The secondary health care that provided at districts hospitals; and

The tertiary health care that provided at the University Hospital Centre (CHU) located in the capital Tirana, where more than one - fifth of the population lives.

The hospital services in Albania respect the right that patients have to inform on everything about health and the health insurance scheme. Each service provided by all providers of hospital services should be full implementation of the referral system in the health service, as well as other acts issued for this purpose by the Ministry of Health in Albania and the health insurance scheme of Albania. Compulsory Health Insurance Fund of Albania, based on the contributions of employees, employers, state and other sources for other people, as provided for in this law, based on the principle of solidarity2. Compulsory Health Insurance Fund, scheme intends to cover the population with health care services, financed by the public and private sector, according to health insurance law.

In the Republic of Albania, the hospital services provide full servives based on yearly legal contract, between Fund and the management of hospitals. The hospitals provide all the services, in full compliance with the instructions and the normative acts adopted by the Ministry of Health and the Administrative Council of Fund of Albania.

\footnotetext{
1 Social Insurance Institute

2 Fjoralba Memia (2014) "The benefits of Compulsory Health Insurance Fund of Albania"
} 
Standards and norms set for hospital services by the Ministry of Health, Clinical Practice Guidelines (CPG) and Clinical Practice Protocols (CPP) approved by Ministry of Health, General Regulation of the operation of the hospital as well as the obligations under this regulation defines the services and functions.

\section{The list of reimbursable drugs}

In Albania, a list of reimbursable drugs applied, as a part of the system knowed as the reimbursement list. Every year, in the list is currently different drugs on the reimbursement list (patent drugs, generic drugs and drugs with trade name). A generic drug is a pharmaceutical product, usually intended to be interchangeable with an innovator product, manufactured without a license from the innovator company and marketed after the expiry date of the patent or under other exclusive rights ${ }^{1}$. Over recent years, several attempts have been made to enhance the reimbursement list in terms of including additional drugs and, at the same time, lower the total expenditure by introducing generic versions. Even that, the trend the presence of generic drugs on the reimbursement list is very important to upgrade the health insurance sector in Albania.

Compulsory health care insurance finances compulsory insurance services packages that include the following:

Reimbursable drugs by the list of health insurance found

Visits, examinations and medical treatments in public primary health care centres and public hospitals;

Visits, examinations and medical treatments in private primary health care providers and private hospitals;

Drugs, medical products and treatments from contracted health service providers.

During the year 2014, after the approval and the implementation for the first time of the health packages ${ }^{2}$ the cost of which was accurately defined ${ }^{3}$, the health insurance scheme established a unified standard both in public and private hospitals, opening for the first time the road to a change in the way of hospitals financing, not according to an historic budget but according to real needs of Albanian population. This is a significant step, which the strategy of implementation of social health insurance scheme undertook in order to implement faires policies concerning the health coverage in Albania.

\section{Chapter II}

\section{The health insurance scheme based in Albania}

\subsection{The principles of health insurance scheme in Albania}

Compulsory health insurance scheme aims health coverage of the population, through the following principles:

Compulsory and voluntary insurance;

Solidarity

Equal access to all citizens of Albania

Efficiency and quality in health care financing

Partnership relations between purchaser, provider and beneficiary

Free choise of Albanian doctor

The basis for the calculation of the contribution is the gross wage of the insured individual. The State's contribution for the economically non active individuals is based on the consumption per capita of the health service, indexed with inflation coefficient. Consumption per capita of the health service is determined by the Fund of Albania and is approved by the

\footnotetext{
${ }^{1}$ D. Xhafaj and L.Malaj (2014) "The presence of Generic Medicines on Albanian reimbursement list over recent years", WJPPS

${ }^{2}$ DCM no. 308, dt.21.05.2014 "On approval of the package of health services to be financed from the Fund of compulsory health care hospital service"

${ }^{3}$ Order no. 258, dated 17.06.2014, the Ministry of Health "On approval Courier Services protocols to be financed by the Fund Security Compulsory Health Care".
} 
Assembly of the Fund together with the annual budget. The basis for the calculation of self-employed contribution is the double of the minimal wage to the effect of contributions calculation. The minimal wage to the effect of self-employed contributions calculation in the city and village is defined by Council of Ministers of Albania decision.

\subsection{The contribution rate of Albania}

The Contribution rate of the compulsory health insurance is $3.4 \%$ of the basis for the contributions calculation. Contributions for the employed are paid $50 \%$ by the employer and $50 \%$ by the employee. The contribution collection collects from General Tax Directorate compulsory health insurance contributions from the employers, for employees and self-employed and transfers them to the Fund, in compliance with the relevant legislation in force. The Social Insurance Institute of Albania, collects and transfers to the Fund of Albania the compulsory health insurance contributions of the self-employed in agriculture (the farmers). The Fund of Albania is responsible for the calculation and collection of the voluntary health insurance contributions. The Fund of Albania collects contributions from the State Budget for the economically inactive population.

Table No 1: The revenues from contributions for health insurance in Albania

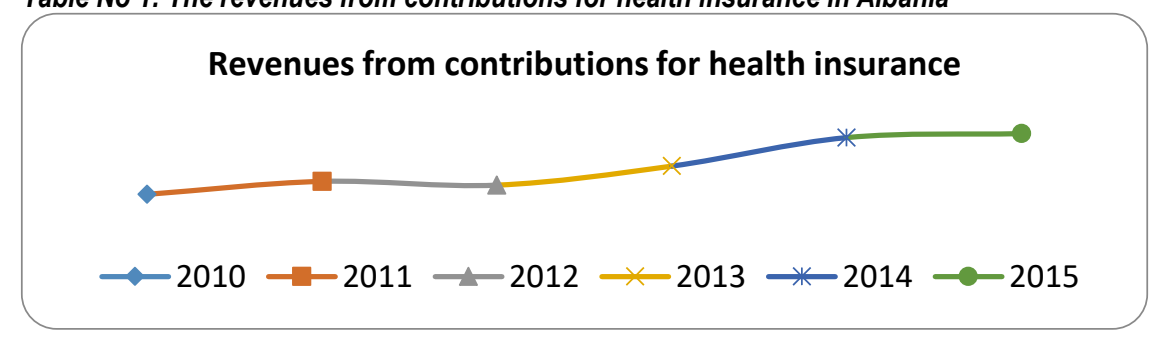

\subsection{Categories benefiting from the health insurance scheme in Albania}

In the Albania every citizen, who pays health insurance contributions or whom the state pays is insured and benefits from the health insurance scheme in country. Compulsory health insurance and payment of relevant contributions in Albania are mandatory for all economically active persons with permanent residence in Albania as:

Economically active people: means all the employed, self-employed, employers and people with regular incomes from personal and real estates or other similar sources.

Economically non-active people: means all the individuals, whose contribution's payment is financed from the state's budget or other sources, as defined by law.

Employed people: means all the individuals that are employed by an employer.

Employer: means all the individuals, either natural or legal, who hire other people and pay them a reward for the performed job, according to the job legislation.

Self-employed: implies all the individuals who work for themselves, as handicraftsmen, small businessmen, consultants, sole owners of a business, farmers and other crafts similar to them, according to the job legislation.

Contributors: implies all natural and legal persons, just like employers, employees, self-employed and the state, who are obliged to pay contributions to the Compulsory Healthcare Insurance Fund in compliance with the law'.

Beneficiaries: implies the individual, who is entitled to use health care services according to the compulsory health care insurance scheme or benefit reimbursement of health services costs, according to a compulsory health insurance contract.

\footnotetext{
1 Law no.10383, dated 24.02.2013, "On compulsory healthcare insurance in the Republic of Albania"
} 
Direct payments: implies payments made from beneficiaries of the compulsory health care insurance for health services packages, regardless of the payment of contributions of the compulsory health care insurance scheme.

Exclusion from benefits: implies health services, drugs, and medical equipment, which are not financed by compulsory health care insurance, but are paid totally by the patient.

Price: is the monetary payment for the provision of health care services.

The benefit package from the compulsory health care insurance: implies the standard of health services benefits, which includes the primary health care and hospital care services, reimbursed drugs and drugs for hospital usage as well as medical facilities.

Unpaid family worker: implies a family member who works and cohabits with a self-employed and does not have any other occupation.

The compulsory health insurance of Albania, covers also, the following categories of economically non-active people, whose contribution's payment is financed by the State Budget or other sources as provided:

people benefitting from Social Insurance Institute;

people benefitting economic assistance or disability payments, in accordance with the relevant legislation;

people who are registered as unemployed-jobseekers at the National Employment Service;

foreign asylum seekers in the Republic of Albania;

children under the age of 18 years old;

pupils and students under 25 years old unless they have incomes from business activities;

categories of persons defined by special laws.

\section{Recommandation}

In the Republic of Albania, the strategy of implementation of social health insurance scheme is the only way to manage and to develop health services. In order to improve quality the strategy needs contribution collection to become more effective with transparent co-payment system. It is interest of the health insurance scheme, to determine the contribution of the Albania people in order to generate resources for adequate health care of population. Improved legislation concerned, radically improved services, health facilities for the population, categories of different residents who are determined by special ways are some of the strategies of the social health insurance scheme of Albania. The purpose of this abstract is to provide a concise description and recommendation of the strategy of implementation of social health insurance scheme in Albania. To develop the scheme of health insurance the following steps are:

The new role of the organization of the health insurance scheme of Albania as an autonomous public Fund in Albania.

A clear indication of the changes to the funding primary health care services.

A clear indication of the changes to the funding hospital health care services.

The new responsibilities of the health insurance scheme of Albania.

A needs of plan for training and upgrading the scheme.

A new financial resources for the health insurance scheme.

Creating the Health card of the residents of Albania.

Creating the electronic registration of the residents of Albania

Even those, in Albania the health scheme system have the opportunities to improve data and information about the benefiting categories from the health insurance scheme. Improved all the economically active e non-active persons with 
permanent residence in Albania is manadatory to improve the functions of the implementation of health insurance scheme in Albania.

\section{References}

[1] Law No. 7870, "On health insurance in the Republic of Albania", as amended, (1994)

[2] Law no. 8417, "Constitution of the Republic of Albania" (1998)

[3] Law no. 10383, "On compulsory healthcare insurance in the Republic of Albania"(2013)

[4] Promulgated by decree no. 6920, dated 8.03.2011 of the President of the Republic of Albania, Promulgated by decree no. 8150, dated 02.05.2013 of the President of the Republic of Albania, Promulgated by decree no. 8451, dated 30.12.2013 of the President of the Republic of Albania, DCM no. 140, "On the financing of hospital care scheme mandatory health care Insurance" (2010)

[5] Enkelejda Avdi (2013) "The Autonomy and Financial Sources, Key Factors in the Performance of Health Insurance Scheme: Case of Albania"

[6] Fjoralba Memia (2014) "The benefits of Compulsory Health Insurance Fund of Albania"

[7] Hysi E, Zyba E, (2008) "The autonomy of public health insurance of Albania"

[8] Lindenlaub Yvonne, Manthei Galina and Schulte Ortwin, EU - Health insurance systems in

[9] Comparison, differences and common denominators, Consultancy Project on Health sector reform in Albania, Berlin, (2008).

[10] OECD (2008) "Health: Statistics and Indicators for 30 Countries"

[11] OECD (2015) "Health policies, a list of latest publications"

[12] OECD (2014), "Potential years of life lost, all causes, females", Health: Key Tables from OECD, No. 16.

[13] OECD (2016), Hospital beds (indicator): Accessed on 27 November 2016)

[14] UBC Health care funding web site, with many resources http://healthcarefunding.ca/

[15] WHO (2008) "Overview of Health Care Financing"

[16] WHO (2015) "Using available resources in the most efficient and equitable way"

[17] Open data (2016) "Financing of health pr capita from the government budget"

[18] The Ministry of Health (2016) "Financing of health per capita from the government budget"

[19] INSTAT (2016) "The statistics of Albanian population" 